\title{
Evaluating the effect of the statistical downscaling method on monthly precipitation estimates of global climate models
}

\author{
Ozbuldu M.* and Irvem A. \\ Department of Biosystems Engineering, Faculty of Agriculture, Hatay Mustafa Kemal University, 31040 Antakya, Hatay, Turkey \\ Received: 26/10/2020, Accepted: 20/05/2021, Available online: 13/06/2021 \\ *to whom all correspondence should be addressed: e-mail: mustafaozbuldu@mku.edu.tr \\ https://doi.org/10.30955/gnj.003458
}

\section{Graphical abstract}

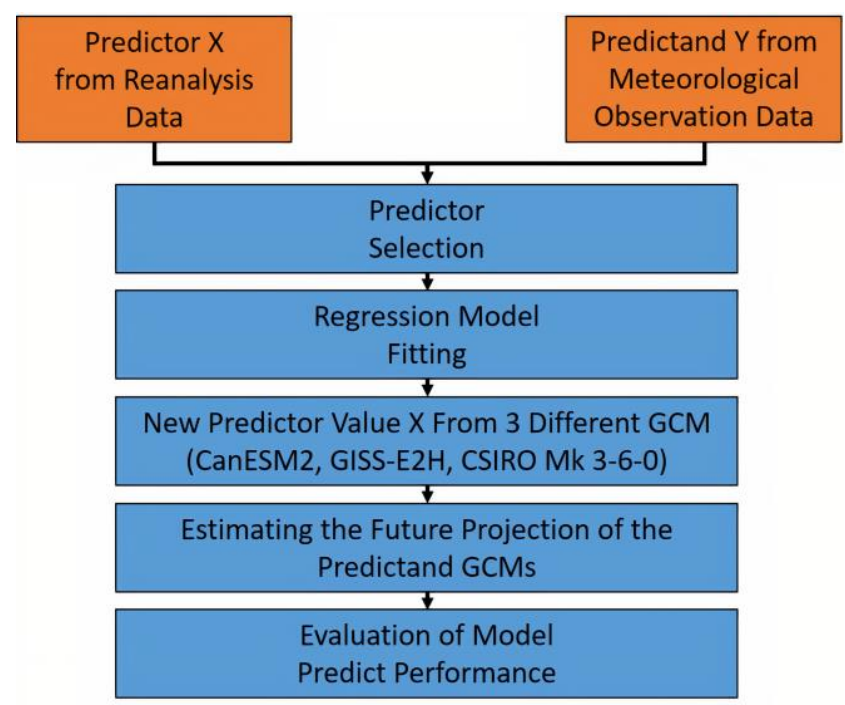

Abstract

Researches to foresee the possible effects of climate change on the environment and living beings for taking necessary precautions on time have increased in recent years. In the improvement of these studies, especially the reduction of estimation errors by downscaling the outputs of global climate models played an important role. In this study, the effect of the statistical downscaling method on improving the prediction accuracy of global climate models (GCM) was investigated. For this purpose, a statistical downscaling method based on multiple linear regression was applied to improve monthly precipitation estimates of 3 different GCM (CanESM2, GISS-E2H, and CSIRO Mk 3-6-0) used in future climate predictions. The effect of this method on improving GCM prediction accuracy was determined by comparing the results obtained as a result of scale reduction with the results obtained from the observation station. The predictive parameters for global climate models were determined using downscaling methods by applying correlation analysis for the study area. As a result of this analysis, it was seen that the air temperature and specific humidity values at the pressure level of $925 \mathrm{hPa}$ and the geopotential height value at the
$300 \mathrm{hPa}$ pressure level had the best correlation for the years 1970-2005. The usability of three different global climate models for the forecast of future precipitation in the Antakya district of Hatay province was investigated using multiple linear regression analysis, one of the downscaling methods. As a result of the statistical analysis, it was seen that the use of the downscaling method increased the accuracy of all prediction models.

Keywords: GCM, statistical downscaling, predictor selection, reanalysis data, hatay.

\section{Introduction}

In recent climate studies, the negative effects of greenhouse gases on the atmosphere, environment and living things are among the most researched topics. While investigating these effects, it is of great importance to predict the changes of climatic factors at different times and locations and to evaluate their potential effects (Tolika et al., 2008; Wang et al., 2014).

It is predicted that sudden and abnormal adverse effects on water supply and crop productivity due to temperature increase and irregular rainfall caused by climate change (Moallim et al., 2016). Predicting climate change and its possible effects at an acceptable level of confidence has a vital role in producing long-term solutions to the effects of global warming. Therefore, it is very important to develop climate models necessary for future prediction (Jia et al., 2019; Li et al., 2020).

Global Climate Models (GCMs) are models used to predict the effects of future climate change on meteorological parameters under different climate scenarios. In addition, they also allow examining the effect of increasing greenhouse gas emissions on climatic variables (Askari et al., 2020). However, the spectral resolutions of most GCM models are not sensitive enough to predict local climatic events. Therefore, downscaling methods are applied to produce data sets with higher resolution than GCM outputs (Maraun et al., 2010; Titus et al., 2013).

There are many downscaling methods in the literature based on various theorems. These methods are basically divided into two as "dynamic" and "statistical" (Kostopoulou et al., 2007). Dynamic methods have the 
advantage of simulating the regional climate at higher resolutions, but they are quite costly and computationally complex (Sachindra, 2014; Zhang and Yan., 2015). On the other hand, the ease of use of statistical methods has led many researchers to use such methods (Kostopoulou et al., 2007). Statistical downscaling methods have been developed to establish quantitative relationships between large-scale atmospheric variables and local surface variables (Fistikoglu and Okkan., 2011). Various regression analyzes are used as statistical scale reduction method (Maraun et al., 2010). These; linear regression analysis (Cheng et al., 2008), canonical correlation analysis (Chen and Chen, 2003), singular value decomposition (Busuioc et al., 1999) and artificial neural networks (ANN) methods (Pryor and Schoof, 2020).

Huth (2002) evaluated the best downscaling methods to be applied in GCM models and stated that the Multiple Regression Analysis method produced the best estimates.

Kostopoulou et al., (2007) examined the estimation ability of three different downscaling techniques in order to simulate the seasonal maximum and minimum temperatures in Greece. They used atmospheric parameters obtained at pressure levels between 1000-500 $\mathrm{hPa}$ as predictors. Multiple linear regression analysis and canonical correlation analysis methods gave values close to both the standard deviation and the mean of the observed values in the estimation of maximum temperature and minimum temperatures.

Tolika et al., (2008) used the outputs they obtained from the global climate model in two different scaling down methods to predict future climate events. As a result of their analysis, they stated that the multiple linear regression (MLR) method made good predictions. In addition, they explained that the downscaling methods were more successful in predicting the winter months compared to other months.

Mishra et al., (2014) applied the multiple linear regression downscaling model to the daily precipitation data obtained from the global climate model to increase the prediction accuracy. They used NCEP re-analysis data to calibrate the model. As a result of the analysis, they explained that the scale reduction method increases the prediction accuracy of the model.

Malha et al., (2019) in their study aimed to increase the accuracy of future precipitation prediction with the global climate model. For this purpose, they examined the effect of multiple linear regression downscaling method. As a result, they explained that the multiple linear regression analysis gave good results for the study area.

Al-Mukhtar and Qasim (2019) used CanESM2 model to predict future temperature and precipitation amounts, and multiple linear regression model as statistical downscaling method. They used NCEP re-analysis data as predictors in the model. As a result of the study, they explained that with the downscaling method, the global climate model can predict temperature and precipitation data at an acceptable level for the study area.
The aim of this study is to establish the adequate model that will predict monthly precipitation amounts in the future by using downscaling methods in different global climate models and to evaluate the model results by applying the established model in Hatay Antakya district.

\section{Materials and methods}

\subsection{Study area}

The study area where the model will be applied is Antakya district of Hatay province, Turkey located between $36^{\circ} 10^{\prime} \mathrm{N}$ latitude and $36^{\circ} 06^{\prime} \mathrm{E}$ longitude and location of the study area is given in Figure 1. It is $80 \mathrm{~m}$ above sea level and has surface area of $610 \mathrm{~km}^{2}$. Antakya has Mediterranean climate that generally mild winter seasons and arid summer with an average annual temperature of $16-21^{\circ} \mathrm{C}$ and rainfall of 570-1,160 mm. (Doğanlar and Atmaca, 2011; Karabulut, 2015).

It is located between the Amanos mountains in the north and the Cebel-i Akra mountains in the south. The Orontes river, which runs through the middle of the region, is the main river system flowing from Syria to the Amik plain and then into the Mediterranean. This plain is located in the northeast of the study area and has great potential for agricultural crop production (Irvem and Topaloglu, 2012).

The reason why this region was chosen as the study area is the floods seen during the high rainy seasons. It is very important to be able to make an accurate estimation of precipitation in order to take the necessary precautions against these floods. In addition, being able to accurately predict precipitation, which is a very effective climate variable in agricultural production, which is important for the region, will play an important role in increasing agricultural productivity.

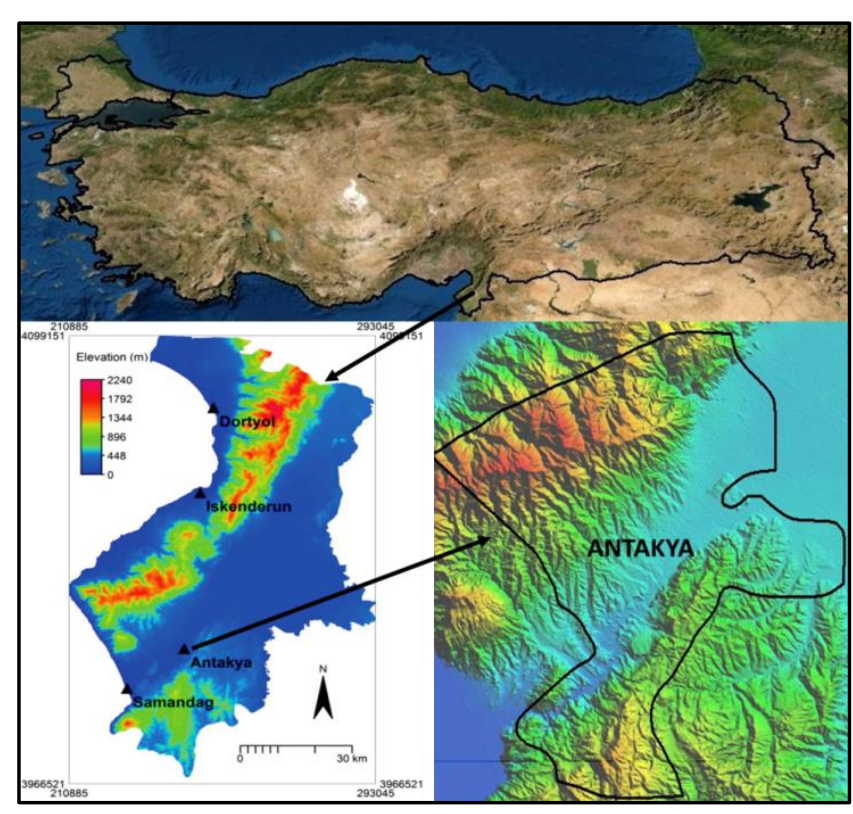

Figure 1. Study area

\subsection{Meteorological data set}

The monthly precipitation amounts observed for the district of Hatay Antakya between 1970 and 2019 were 
obtained from the observation station of the General Directorate of Meteorology.

\subsection{Reanalysis data set}

Atmospheric variables used for the study area and their properties are given in Table 1 . The monthly averages of these variables for the years 1970-2005 were obtained from the National Environmental Forecast Center (NCEP)/National Atmospheric Research Center (NCAR) reanalysis data set. The horizontal resolution of the data is $2.5^{\circ}$ latitude $\times 2.5^{\circ}$ longitude, and the vertical resolution is 17 constant pressure levels (Goyal and Ojha., 2012).

\subsection{GCM data set}

In this study as global climate models (GCM), CanESM2 (Arora et al., 2011) produced by Canada Climate Center, GISS-E2-H (Schmidt et al., 2012) produced by NASA Goddard Institute and CSIRO Mk-3-6-0 (Rotstayn et al., 2012) produced by Australian Queensland Climate Change Center are used. The outputs of these models shown in Table 1 for the study area were obtained from the internet address https://esgf-node.IInl.gov/search/cmip5/ for the years 1970-2019.

Table 1. Predictive variables for the downscaling method

\begin{tabular}{|c|c|c|c|}
\hline No & Predictors & Code & Unit \\
\hline 1 & Air Temperature (300 hPa) & AirT300 & ${ }^{\circ} \mathrm{C}$ \\
\hline 2 & Air Temperature (500 hPa) & AirT500 & ${ }^{\circ} \mathrm{C}$ \\
\hline 3 & Air Temperature (850 hPa) & AirT850 & ${ }^{\circ} \mathrm{C}$ \\
\hline 4 & Air Temperature (925 hPa) & AirT925 & ${ }^{\circ} \mathrm{C}$ \\
\hline 5 & Geopotential Height (300 hPa) & Hgt300 & $\mathrm{m}$ \\
\hline 6 & Geopotential Height ( $500 \mathrm{hPa}$ ) & Hgt500 & $\mathrm{m}$ \\
\hline 7 & Geopotential Height (850 hPa) & Hgt850 & $\mathrm{m}$ \\
\hline 8 & Geopotential Height (925 hPa) & Hgt925 & $\mathrm{m}$ \\
\hline 9 & Relative Humidity (300 hPa) & Rhum300 & $\%$ \\
\hline 10 & Relative Humidity $(500 \mathrm{hPa}$ ) & Rhum500 & $\%$ \\
\hline 11 & Relative Humidity (850hPa) & Rhum850 & $\%$ \\
\hline 12 & Relative Humidity (925 hPa) & Rhum925 & $\%$ \\
\hline 13 & Specific Humidity (300 hPa) & Shum300 & $\mathrm{g} \mathrm{kg}^{-1}$ \\
\hline 14 & Specific Humidity (500 hPa) & Shum500 & $\mathrm{g} \mathrm{kg}^{-1}$ \\
\hline 15 & Specific Humidity ( $850 \mathrm{hPa}$ ) & Shum 850 & $\mathrm{~g} \mathrm{~kg}^{-1}$ \\
\hline 16 & Specific Humidity (925 hPa) & Shum925 & $\mathrm{g} \mathrm{kg}^{-1}$ \\
\hline 17 & U-wind $(300 \mathrm{hPa})$ & Uwnd300 & $\mathrm{m} \mathrm{s}^{-1}$ \\
\hline 18 & U-wind $(500 \mathrm{hPa})$ & Uwnd500 & $\mathrm{m} \mathrm{s}^{-1}$ \\
\hline 19 & U-wind $(850 \mathrm{hPa})$ & Uwnd850 & $\mathrm{m} \mathrm{s}^{-1}$ \\
\hline 20 & U-wind (925 hPa) & Uwnd925 & $\mathrm{m} \mathrm{s}^{-1}$ \\
\hline 21 & V-wind $(300 \mathrm{hPa})$ & Vwnd300 & $\mathrm{m} \mathrm{s}^{-1}$ \\
\hline 22 & V-wind $(500 \mathrm{hPa})$ & Vwnd500 & $\mathrm{m} \mathrm{s}^{-1}$ \\
\hline 23 & V-wind $(850 \mathrm{hPa})$ & Vwnd850 & $\mathrm{m} \mathrm{s}^{-1}$ \\
\hline 24 & V-wind (925 hPa) & Vwnd925 & $\mathrm{m} \mathrm{s}^{-1}$ \\
\hline
\end{tabular}

\subsection{Selection of predictors}

The statistical downscaling method is based on the establishment of empirical relationships between coarsescale atmospheric and local climate characteristics. Selection of appropriate predictor variables is one of the most important steps in downscaling methods applied to improve estimates (Osman and Abdellatif, 2017). This method is used to determine the predictor showing the most appropriate correlation between precipitation measurements obtained from meteorological stations and the data obtained from the reanalysis data set (Al-Mukhtar and Qasim, 2019). The downscaling model are used to build the linear relationship between predictand (observed precipitation) and one or more than one independent atmospheric variables as predictor (NCEP reanalysis data) (Mahla et al., 2019). The most important assumption of statistical downscaling method is that the relationship between climatic parameters will not change as the climate changes. Therefore, it is accepted that the statistical relationships between the same scale predictand and predictors will always remain the same (Trzaska and Schnarr, 2014). There are many atmospheric variables that can be used as predictors. However, using very many estimators in the model may cause an increase in uncertainty caused by an unrelated parameter, and using very few estimators may cause poor precipitation and temperature estimates (Zhang and Yan., 2015). Therefore, correlation analysis and $\mathrm{P}$ value approaches are used to determine the optimum number of variables. These statistical approaches are regarded as a measure of the relationship between predictor and observational data. Smaller $P$ value $(P<0.05)$ and higher correlation mean that there is a good correlation between variables (Yang et al., 2017).

Correlation coefficients of variables with the highest correlation are selected for model formulation as a result of correlation analysis between predictive variables (reanalysis) and observation (meteorological station) data 
(Behera et al., 2016). In this study, among the variables given in Table 1, the variables to be used in the scale reduction method were selected as a result of the correlation analysis of Pearson (Pearson,1896) and Spearman's Rank (Spearman,1904).

\subsection{Multiple linear regression analysis}

MLR analysis is used to examine the relationship of these variables with the dependent variable in the case of more than one variable. If variables are defined as $X_{i}^{1}, X_{i}^{2}, \ldots, X_{i}^{n}$ the linear regression model is expressed by Eq. 1 (Lee and Singh, 2019).

$$
Y_{i}=\beta_{0}+\beta_{1} X_{i}^{1}+\beta_{2} X_{i}^{2}+\cdots+\beta_{n} X_{i}^{n}
$$

A larger scale variable is more effective than a variable with a smaller scale in the MLR downscaling method. For this reason, the standardization process has been applied as a pre-treatment in downscaling. The Eq. 2 is used for standardization (Goyal and Ojha, 2012).

$$
X_{i}=\frac{\left(X_{i}^{\mathrm{Org}}-\bar{X}\right)}{s_{x}}
$$

where; $X_{i}^{\text {Org }}$ is the value of the variable before it is standardized, $\bar{X}$ is the average of the values of the variable, and sxis the standard deviation of the values the variable takes.

$$
\hat{Y}_{i}^{\text {Org }}=\left(\hat{Y}_{i} \times s_{y}+\bar{Y}\right)
$$

where; $\hat{Y}_{i}^{\text {Org }}$ is precipitation estimation obtained by the downscaling method, $s_{y}$ is standard deviation of precipitation amounts for the base period (1970-2005) and $\bar{Y}$ is the average of precipitation for the base period (19702005). The issue to be considered is that while standardization is applied to the variables obtained from the next period (2006-2019) outputs of the global climate model, the standard deviation and average of the base period variables as standard deviation and mean are taken into account (Lee and Singh, 2019).

\subsection{Performance evaluation criteria}

Statistical criteria used in the study to check the accuracy of the estimation data of the models; root mean squares error (RMSE), percent bias (PB), Willmott's index of agreement $(d)$ and performance index $\left(C^{\prime}\right)$. The prediction abilities of the data were evaluated using the classification given in Table 2.

Pbias are used to determine how far the model predicted values are in the negative or positive direction from the observed values. While positive values indicate that the observed values are greater than the simulation values, negative values indicate the opposite situation (Gupta et al., 1999)

$$
\text { Pbias }=100\left(\sum \text { Obs }_{i}-\text { Predict }_{i} / \sum \text { Obs }_{i}\right)
$$

The value of RMSE should always be positive and it is desired to be close to zero. It indicates that the smaller the value, the better the performance of the model. RMSE provides information about the short-term performance of correlations by providing comparison of the deviation between model outputs and observed values (Ghorbani et al., 2018).

$$
\mathrm{RMSE}=\sqrt{\frac{1}{n} \sum\left(\text { Predict }_{i}-\text { Obs }_{i}\right)^{2}}
$$

The Willmott index of agreement (d) shows the degree of fit between observed and predicted measurements between 0 and 1 . The closer the result is to 1 , the better the model performance is determined (Willmott, 1981).

$$
d=\frac{\sum\left(\mathrm{Obs}_{i}-\text { Predict }_{i}\right)^{2}}{\sum\left(\left[\text { Predict }_{i}-\text { Obs }_{\text {mean }}\right]+\left[\text { Obs }_{i}-\text { Obs }_{\text {mean }}\right]\right)^{2}}
$$

The performance index $\left(C^{\prime}\right)$ combines accuracy and precision criteria in the relationship of the model with predictive data. Pearson's linear correlation coefficient, which measures the degree and direction of distribution between variables, was used as precision criteria. Willmott's index of agreement was chosen as the accuracy criterion because it measures the degree of fit between the predicted and observed data. The performance index of the model was calculated by Eq. 7 and evaluated using Table 2 (Santos et al., 2020).

$$
\begin{aligned}
C^{\prime}= & \text { Correlation Coefficient }(C C) \\
& * \text { Willmott's index of agreement }(d)
\end{aligned}
$$

Table 2. Model performance evaluation table (Moriasi et al., 2007; Santos et al., 2020).

\begin{tabular}{ccc}
\hline Classification & $\mathbf{C}^{\prime}$ & PBias \\
\hline Very Good & $0.75-1.00$ & $< \pm 10$ \\
\hline Good & $0.65-0.75$ & $\pm 10- \pm 15$ \\
\hline Satisfactory & $0.60-0.65$ & $\pm 15- \pm 25$ \\
\hline Unsatisfactory & $<0.50$ & $> \pm 25$ \\
\hline
\end{tabular}

\section{Results and discussion}

\subsection{Results of predictors selection}

In determining the predictors, the results of the statistical analysis made for the base period of 1970-2005 in order to determine the correlation of the variables with the observed precipitation data are given in Table 3 and Predictor selection was made by considering Table 4 and predictors with high correlation values were used for formulation.

According to the results, it was seen that air temperature and specific humidity values at $925 \mathrm{hPa}$ pressure level and geopotential height values at $300 \mathrm{hPa}$ pressure level had a better correlation than other atmospheric variables. Therefore, these data were used as predictor variables (Fistikoglu and Okkan., 2011). The reason for the low correlations of predictor variables is estimated to be due to the heterogeneity of precipitation (Al-Mukhtar and Qasim, 2019). 


\subsection{Results of downscaling method}

Before applying the downscaling method, the standardization process was applied to the predictor variables for the base period of 1970-2005. The coefficients of the variables obtained as a result of the regression analysis between the standardized predictor variables and standardized rainfall measurements are given in Table 5 . The formula obtained by using the coefficients of the predictive variables as a result of the analysis is given in $\mathrm{Eq}$ 8.

$$
\begin{aligned}
Y_{i}= & -0,88 * \text { AirT925 +0,36 } \\
& * \text { Hgt300 }-0,08 * \text { Shum925 }
\end{aligned}
$$

Finally, the predictor variables from the GCM model were obtained for the base period (1970-2005) and the next period (2006-2019). By standardizing these variables, $X=\left[1, X_{i}^{1}, X_{i}^{2}, \ldots, X_{i}^{n}\right]$ value was obtained. The corrected estimates for 2006-2019 are calculated using Eq. 9 and 10. Monthly averages of the estimation results calculated for each GCM are given in Table 6.

$$
\begin{aligned}
\hat{Y}_{\text {Year,Month }}= & {\left[\begin{array}{c}
1 \\
X_{i}^{1} \\
X_{i}^{2} \\
X_{i}^{3}
\end{array}\right] *\left[\begin{array}{c} 
\\
0 \\
\beta_{1} \\
\beta_{2} \\
\beta_{3}
\end{array}\right] } \\
\hat{Y}_{\text {Year,Month }}^{\text {Org. }=} & \left(\hat{Y}_{\text {Year,Month }} \times s_{\text {Yağıs, 1970-2004 }}\right) \\
& +\bar{Y}_{\text {Precipitation,1970-2004 }}
\end{aligned}
$$

When the results of the forecast are examined, it is seen that precipitation forecasts are better in winter months and worse in summer months. The poor forecasts seen in the summer months are thought to be due to the fact that the model still predicts precipitation even though there is no precipitation during these months.

\subsection{Performance evaluation of downscaling method}

By applying the MLR downscaling method to three different climate models, the forecast data obtained for the

Table 3. Results of correlation analysis of predictor variables future period (2006-2019) and the actual data obtained from meteorology for the same years were statistically compared. $\mathrm{R}^{2}$, MAPE, Pbias, RMSE, Willmott's index of agreement values were calculated for each GCM and the results are given in Table 7 .

\subsubsection{CanESM2}

It is seen in Figure 2 that the predictions of GCM after downscaling are much better than the estimates before downscaling for all months. The results of $R^{2}$ was found to be more than 0.9 , which indicated good correlation between observed and downscaled precipitation.

When the RMSE results were examined, it was seen that the CanESM2 model decreased from 82.52 to 21.94 which indicates less discrepancy between observed and downscaled time series.

Similarly, PBias values decreased for from 72.22, to 7.07 . These results show that the downscaling method has reduced the amount of error in the estimations resulting from the coarse resolution of GCM models.

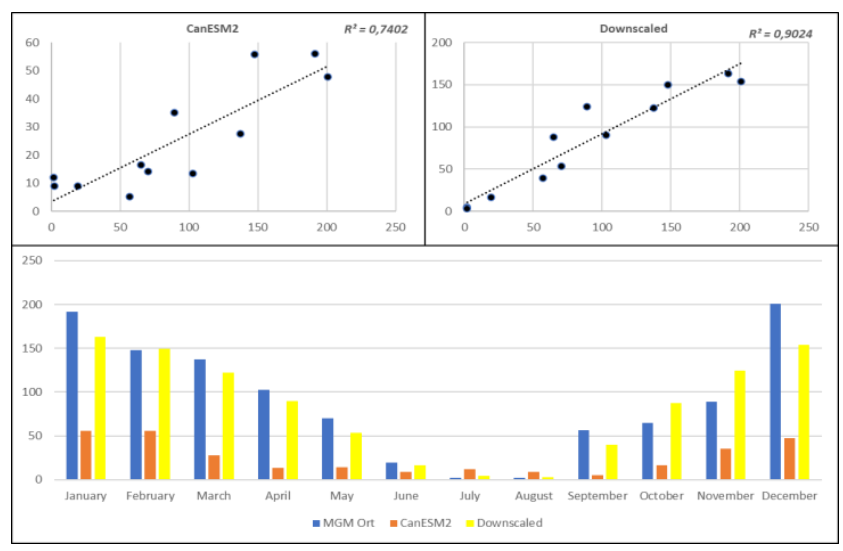

Figure 2. Comparison of the CanESM2 model's estimates before and after statistical downscaling

According to $C^{\prime}$ values, it was seen that the accuracy performance of the GCM model for estimation increased above 0.80 by the downscaling method and when referring Table 2, the model estimation results could be considered quite good.

\begin{tabular}{cccccc}
\hline Predictor variable & Pearson & Spearman's rank & Predictor variable & Pearson & Spearman's rank \\
\hline AirT300 & $-0,538$ & $-0,661$ & Shum300 & $-0,434$ & $-0,594$ \\
\hline AirT500 & $-0,565$ & $-0,687$ & Shum500 & $-0,533$ & $-0,682$ \\
\hline AirT850 & $-0,509$ & $-0,612$ & Shum850 & $-0,466$ & $-0,554$ \\
\hline AirT925 & $-\mathbf{0 , 6 0 6}$ & $-\mathbf{0 , 7 2 8}$ & Shum925 & $-\mathbf{0 , 5 9 5}$ & $-\mathbf{0 , 7 2 2}$ \\
\hline Hgt300 & $-\mathbf{0 , 5 8 7}$ & $-\mathbf{0 , 7 1 3}$ & Uwnd300 & $-0,116$ & $-0,125$ \\
\hline Hgt500 & $-0,556$ & $-0,679$ & Uwnd500 & $-0,126$ & $-0,149$ \\
\hline Hgt850 & $-0,429$ & $-0,496$ & Uwnd850 & $-0,358$ & $-0,409$ \\
\hline Hgt925 & 0,088 & $-0,102$ & Uwnd925 & $-0,319$ & $-0,406$ \\
\hline Rhum300 & 0,024 & $-0,021$ & Vwnd300 & $-0,047$ & $-0,066$ \\
\hline Rhum500 & $-0,001$ & $-0,020$ & Vwnd500 & $-0,033$ & $-0,031$ \\
\hline Rhum850 & 0,369 & $-0,430$ & Vwnd850 & $-0,042$ & $-0,052$ \\
\hline Rhum925 & $-0,371$ & $-0,432$ & Vwnd925 & $-0,092$ & $-0,123$ \\
\hline
\end{tabular}


Table 4. Interpretation of correlation coefficient values (Woo et al., 2018)

\begin{tabular}{cc}
\hline Correlation value & Interpretation \\
\hline $\pm 0.90-1.00$ & Very high correlation \\
\hline $\pm 0.70-0.90$ & High correlation \\
\hline $\pm 0.50-0.70$ & Moderate correlation \\
\hline $\pm 0.30-0.50$ & Low correlation \\
\hline $\pm 0.00-0.30$ & Negligible correlation \\
\hline
\end{tabular}

Table 5 Regression analysis result for the base period

\begin{tabular}{|c|c|c|c|}
\hline & Coefficients & Standard error & $t$ Stat \\
\hline$\beta_{0}$ & 0,00 & 0,04 & 0,00 \\
\hline$\beta_{1}$ & $-0,88$ & 0,23 & $-3,86$ \\
\hline$\beta_{2}$ & 0,36 & 0,16 & 2,32 \\
\hline$\beta_{3}$ & $-0,08$ & 0,15 & $-0,52$ \\
\hline
\end{tabular}

Table 6. Average monthly precipitation estimates between 2006-2019

\begin{tabular}{cccccccc}
\hline \multirow{2}{*}{ Months } & MGM & \multicolumn{3}{c}{ GCM } & \multicolumn{3}{c}{ Downscaled GCM } \\
\cline { 2 - 9 } & Mean precipitation (mm) & CanESM2 & GISS-E2H & CSIRO Mk 3-6-0 & CanESM2 & GISS-E2H & CSIRO Mk 3-6-0 \\
\hline January & 191,56 & 56,04 & 111,81 & 50,86 & 162,85 & 132,28 & 166,93 \\
\hline February & 147,66 & 55,80 & 84,39 & 29,29 & 149,46 & 123,55 & 151,10 \\
\hline March & 137,59 & 27,64 & 54,06 & 23,57 & 122,07 & 109,67 & 116,45 \\
\hline April & 102,99 & 13,53 & 17,31 & 14,89 & 90,13 & 77,29 & 85,75 \\
\hline May & 70,31 & 14,16 & 13,40 & 2,04 & 53,62 & 59,07 & 61,74 \\
\hline June & 19,24 & 8,98 & 10,11 & 0,63 & 16,65 & 41,01 & 25,00 \\
\hline July & 1,96 & 12,00 & 9,16 & 0,06 & 4,78 & 28,85 & 10,07 \\
\hline August & 2,10 & 8,92 & 14,35 & 0,13 & 3,20 & 21,86 & 14,37 \\
\hline September & 56,91 & 5,11 & 7,74 & 2,52 & 39,69 & 24,66 & 48,29 \\
\hline October & 64,92 & 16,46 & 25,33 & 25,27 & 87,83 & 47,56 & 75,20 \\
\hline November & 89,14 & 35,14 & 120,99 & 35,94 & 124,23 & 94,47 & 124,58 \\
\hline December & 200,89 & 47,67 & 151,24 & 76,96 & 154,03 & 123,12 & 158,90 \\
\hline
\end{tabular}

Table 7. Performance evaluation of downscaled global climate models

\begin{tabular}{ccccccc}
\hline & & $\boldsymbol{R}^{\mathbf{2}}$ & RMSE & $\boldsymbol{d}$ & Pbias & $\boldsymbol{C}^{\prime}$ \\
\hline \multirow{2}{*}{ CanESM2 } & GCM & 0,74 & 82,52 & 0,56 & 72,22 & 0,48 \\
\cline { 2 - 7 } & Downscaled & 0,90 & 21,94 & 0,97 & 7,07 & 0,92 \\
\hline \multirow{2}{*}{ GISS-E2H } & GCM & 0,66 & 54,52 & 0,79 & 42,88 & 0,64 \\
\cline { 2 - 8 } & Downscaled & 0,89 & 34,96 & 0,89 & 2,68 & 0,84 \\
\hline \multirow{2}{*}{ CSIRO-Mk 3-6-0 } & GCM & 0,76 & 82,82 & 0,58 & 75,85 & 0,51 \\
\cline { 2 - 8 } & Downscaled & 0,92 & 20,17 & 0,97 & 4,32 & 0,93 \\
\hline
\end{tabular}

\subsection{2. $C S I R O-M k$ 3-6-O}

When the results of the statistical analysis of CSIRO-Mk 36-0 raw and precipitation data were examined, it was seen in Figure 3 that the application of the downscaling method in this model improved the prediction accuracy quite well compared to the raw data. The coefficient of determination was calculated to above 0.90 . This shows that downscaled data are in a high linear relationship with the data measured from the precipitation observation station. When the RMSE results were examined, the CSIRO-Mk 3-60 model decreased from 82.82 to 20.17 . Similarly, PBias values decreased for the CSIRO-Mk 3-6-0 models from 75.85 7.32. These results show that the downscaling method has reduced the amount of error in the estimations resulting from the coarse resolution of GCM. According to $C^{\prime}$ values, it was seen that the accuracy performance of the GCM model for estimation increased to 0.93 by the downscaling method and when referring Table 2 the model estimation results could be considered quite good.

\subsubsection{GISS-E2H}

Figure 4 shows that the downscaling model estimates give better estimates than the raw GISS-E2H estimates. The determination coefficient was found to be 0.89 when examined in general, this result showed that the relationship between observed and downscaled precipitation was good. However, it was determined that the GCM raw data estimated better than the downscaled data for the summer months. The reason for this is thought to be the unexpected rains and drought events in the study area during these months. Such extreme events are a known phenomenon. These events are very difficult to predict with models. The effect of this phenomenon was seen in the other two GCMs. However, the downscaling method was able to reduce the estimation error a little in CanESM2 and CSIRO-Mk 3-6-0. However, its use in GISS$\mathrm{E} 2 \mathrm{H}$ has failed to predict summer months.

When Table 7 was examined, it was seen that the RMSE values decreased by almost $50 \%$ and Pbias value decreased from 42.88 to 2.68 . These results show that when all months are examined, the downscaled data give more 
similar estimates to the observation data than the raw data. In addition, when the model results are classified according to the calculated $C^{\prime}$ value based on Table 2 , it is seen that the unsatisfactory estimates perform very good after the downscaling model.

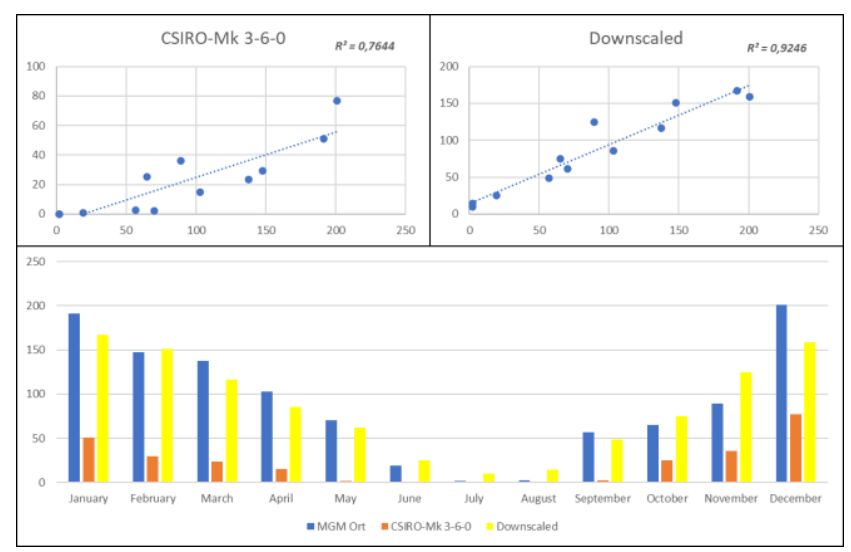

Figure 3. Comparison of the CanESM2 model's estimates before and after statistical downscaling

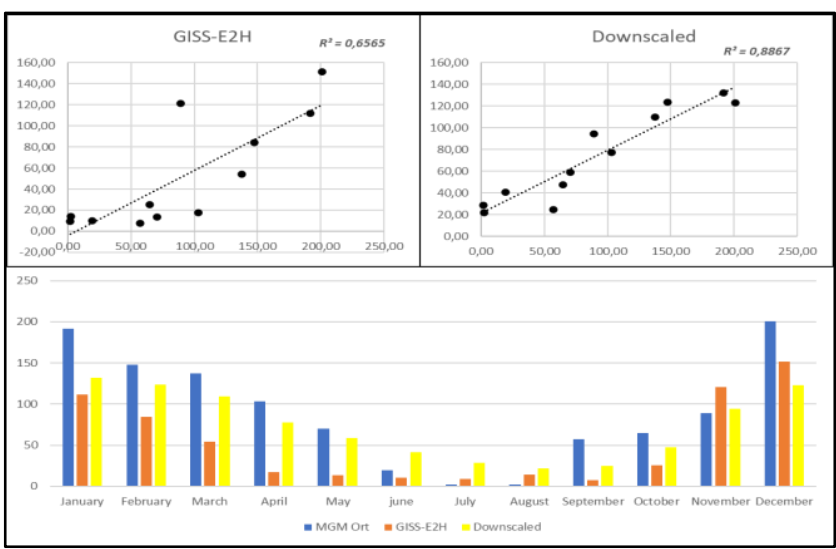

Figure 4. Comparison of the GISS-E2H model's estimates before and after statistical downscaling

\section{Conclusions}

Estimating the impact of climate change on atmospheric variables, which is one of the biggest problems globally today, will allow both taking necessary precautions in advance and minimizing the damages that will occur. For this purpose, it is very important to minimize the prediction errors caused by the low resolution of the global climate model outputs that have been used in recent years.

In this study, the predictor parameters were determined using correlation analysis in the downscaling model created for the study area. As a result of this analysis, it was seen that the air temperature and specific humidity values at the pressure level of $925 \mathrm{hPa}$ and the geopotential height at the $300 \mathrm{hPa}$ pressure level had the best correlation for the years 1970-2005. The downscaling procedure of precipitation of this study was in agreement with other studies (e.g., Al-Mukhtar and Qasim, 2019; Wilby et al., 1998), It has been determined that using atmospheric variables while reducing the coarse scale of precipitation estimates obtained from GCMs is successful in establishing a satisfactory relationship.

In our study, the usability of multiple linear regression analysis was examined to increase the accuracy in monthly precipitation estimates made by three different global climate models (CanESM2, GISS-E2H and CSIRO Mk 3-6-0). As a result of the statistical analysis, the prediction ability $\left(C^{\prime}\right)$ of the CanESM2 model increased from 0.48 to 0.92 , the GISS-E2H model from 0.64 to 0.84 and the CSIRO Mk 3-6-0 model from 0.51 to 0.93 .

Based on these results, it was determined that the use of the downscaling method for all three models increased the prediction accuracy of the models. However, it was determined that the GISS-E2-H model had difficulties in predicting precipitation during the summer months due to the drought and unexpected rainfalls in the study area during these months. CanESM2 was the model that made the closest estimates to the precipitation obtained from the observation stations for all months. Similar to the results of our study; Najafi et al., (2011), Sachindra and Perera (2016), Behera et al., (2016), Mahla et al., (2019) and Al-Mukhtar and Qasim (2019) indicated that MLR could be used for downscaling of monthly rainfall of regions under arid and semi-arid.

With this method, it is seen that the outputs of global climate models can be used in the studies to evaluate the effect of climate change for the study area. In addition, it has been determined that the outputs of these models can be used in agricultural and hydrological models after examining them with the necessary statistical analysis.

\section{References}

Al-Mukhtar M., and Qasim M. (2019). Future predictions of precipitation and temperature in Iraq using the statistical downscaling model, Arabian Journal of Geosciences, 12, 25.

Arora V.K., Scinocca J.F., Boer G.J., Christian J.R., Denman K.L., Flato G.M., Kharin V.V., Lee W.G., and Merryfield M.J. (2011). Carbon emission limits required to satisfy future representative concentration pathways of greenhouse gases, Geophysical Research Letters, 38, L05805.

Askari K.O.A., Kharazi H.G., Shayannejad M., and Zareian M.J. (2020). Effect of Climate Change on Precipitation Patterns in an Arid Region Using GCM Models: Case Study of IsfahanBorkhar Plain, Natural Hazards Review, 21(2), 04020006.

Behera S., Khare D., Mishra P.K., Sahoo S. (2016). Application of statistical downscaling model for prediction of future rainfall in Bhudhabalanga River Basin, Odisha (India), International Journal of Engineering and Advanced Technology, 5(4), 22498958.

Busuioc A., Von Storch H., and Schnur R. (1999). Verification of GCM generated regional seasonal precipitation for current climate and of statistical downscaling estimates under changing climate conditions, Journal of Climate, 12(1), 258272.

Chen D., and Chen Y. (2003). Association between winter temperature in China and upper air circulation over East Asia revealed by canonical correlation analysis, Global and Planetary Change, 37(3-4), 315-325. 
Cheng C.S., Li G., Li Q., and Auld H. (2008) Statistical downscaling of hourly and daily climate scenarios for various meteorological variables in South-central Canada, Theoretical and Applied Climatology, 91, 129-147.

Doğanlar Z.B., and Atmaca M. (2011). Influence of airborne pollution on $\mathrm{Cd}, \mathrm{Zn}, \mathrm{Pb}, \mathrm{Cu}$, and $\mathrm{Al}$ accumulation and physiological parameters of plant leaves in Antakya (Turkey), Water Air Soil Pollut, 214, 509-523.

Fistikoglu O., and Okkan U. (2011). Statistical downscaling of monthly precipitation using NCEP/NCAR reanalysis data for Tahtali River Basin in Turkey, Journal of Hydrologic Engineering, 16(2), 157-164.

Ghorbani M.A., Khatibi R., Karimi V., Yaseen Z.M., and ZounematKermani M. (2018). Learning from multiple models using artificial intelligence to improve model prediction accuracies: application to river flows, Water Resources Management, 32(13), 4201-4215.

Goyal M.K., and Ojha C.S.P. (2012). Downscaling of surface temperature for lake catchment in an arid region in India using linear multiple regression and neural networks, International Journal of Climatology, 32, 552-566.

Gupta H.V., Sorooshian S., and Yapo P.O. (1999). Status of automatic calibration for hydrologic models: Comparison with multilevel expert calibration, Journal of Hydrologic Engineering, 4(2), 135-143.

Huth R. (2002). Statistical downscaling of daily temperature in central Europe, Journal of Climate, 15, 1731-1742.

Irvem A., and Topaloglu F. (2012). Identification of flood risk area in the Orontes river basin, Turkey, using multi-criteria decision analyses, Journal of Food, Agriculture \& Environment, 10 (3), 895-899.

Jia K., Ruan Y., Yang Y., and You Z. (2019). Assessment of CMIP5 GCM simulation performance for temperature projection in the Tibetan Plateau, Earth and Space Science, 6, 2362-2378.

Karabulut M. (2015). Drought analysis in AntakyaKahramanmaraş Graben, Turkey, J. Arid Land,7, 741-754.

Kostopoulou E., Giannakopoulos C., Anagnostopoulou C., Tolika K., Maheras P., Vafiadis M., and Founda D. (2007). Simulating maximum and minimum temperature over Greece: a comparison of three downscaling techniques, Theoretical and Applied Climatology, 90, 65-82.

Lee T., and Singh V.P. (2019). Statistical downscaling for hydrological and environmental applications, Boca Raton: CRC Press, 165.

Li J., Gan T.Y., Chen Y.D., Gu X., Hu Z., Zhou Q., and Lai Y. (2020). Tackling resolution mismatch of precipitation extremes from gridded GCMs and site-scale observations: implication to assessment and future projection, Atmospheric Research, 239, p. 104908.

Mahla P., Lohani A.K., Chandola V.K., Thakur A., Mishra C.D., and Singh A. (2019). "Downscaling of precipitation using multiple linear regression over Rajasthan state". Current World Environment, 14(1), 68-98.

Maraun D., Wetterhall F., Ireson A.M., Chandler R.E., Kendon E.J., Widmann M., Brienen S., Rust H.W., Sauter T., ThemeßI M., Venema V.K.C., Chun K.P., Goodess C.M., Jones R.G., Onof C., Vrac M., and Thiele-Eich I. (2010). Precipitation downscaling under climate change: recent developments to bridge the gap between dynamical models and the end user, Reviews of Geophysics, 48(3), RG3003.
Mishra P.K., Khare D., Mondal A., and Kundu S. (2014). Multiple linear regression based statistical downscaling of daily precipitation in a canal command. Editor: Singh M. Climate Change and Biodiversity: Proceedings of IGU Rohtak Conference, 1, Springer, Japan.

Moallim A.A., Kamal R., Wayakok A., Ahsan A., and Mohamed A.A. (2016). Utilization of global circulation models for climate change impacts assessments on agricultural water and crop production: a review, Asian Journal of Applied Sciences, 4(2), 226-240.

Moriasi D.N., Arnold J.G., Van Liew M.V., Bingner R.L., Harmel R.D., and Veith T.L. (2007). Model evaluation guidelines for systematic quantification of accuracy in watershed simulations, Transactions of the ASABE, 50(3), 885-900.

Najafi M.R., Zwiers F.W., and Gillett N.P. (2016). Attribution of the spring snow cover extent decline in the Northern Hemisphere, Eurasia and North America to anthropogenic influence, Clim Chang, 136(3-4),571-586.

Osman Y.Z., and Abdellatif M.E. (2016). Improving accuracy of downscaling rainfall by combining predictions of different statistical downscale models, Water Science, 30(2), 61-75.

Pearson K. (1896). Mathematical contributions to the theory of evolution III regression heredity and panmixia, Philosophical Transactions of the Royal Society of London Series, 187, 253318.

Pryor S.C., and Schoof J.T. (2020). Differential credibility assessment for statistical downscaling, Journal of Applied Meteorology and Climatology, 59 (8), 1333-1349.

Rotstayn L.D., Jeffrey S.J., Collier M.A., Dravitzki S.M., Hirst A.C., Syktus J.I., Wong K.K. (2012). Aerosol- and greenhouse gasinduced changes in summer rainfall and circulation in the Australasian region: a study using single-forcing climate simulations, Atmospheric Chemistry and Physics, 12, 63776404.

Sachindra D.A., Huang F., Barton A., and Perera B.J.C. (2014). Statistical downscaling of general circulation model outputs to precipitation-part 1: calibration and validation, International Journal of Climatology, 34(11), 3264-3281.

Sachindra D.A. and Perera B.J.C (2016). Statistical Downscaling of General Circulation Model Outputs to Precipitation Accounting for Non-Stationarities in Predictor-Predictand Relationships, PLOS ONE, 11(12), e0168701.

Santos J.F.S., Leite D.C., Severo F.A.S., Naval L.P. (2020). Validating the Mark-HadGEM2-ES and Mark-MIROC5 climate models to simulate rainfall in the last agricultural frontier of the Brazilian North and North-East Savannah, Advances in Research, 21(8), 43-54.

Schmidt G.A., Ruedy R., Hansen J.E., Aleinov I., Bell N., Bauer M., and Cheng Y. (2006). Present-day atmospheric simulations using GISS ModelE: Comparison to in situ, satellite, and reanalysis data, Journal of Climate, 19, 153-192.

Spearman C.E. (1904). Proof and measurement of association between two things, American Journal of Psychology, 15, 72101.

Titus M.L., Sheng J., Greatbatch R.J., and Folkins I. (2013). Improving statistical downscaling of general circulation models, Atmosphere-Ocean, 51(2), 213-225.

Trzaska S., and Schnarr E. (2014). A review of downscaling methods for climate change projections; CIESIN, the Center for International Earth Science Information Network, 
Columbia University, Based at Columbia's Lamont campus in Palisades: New York, NY, USA, 1-42.

Tolika K., Anagnostopoulou C., Maheras P., and Vafiadis M. (2008). Simulation of future changes in extreme rainfall and temperature conditions over the Greek area: a comparison of two statistical downscaling approaches, Global and Planetary Change, 63, 132-151.

Wang W.G., Yu Z.B., Zhang W., Shao Q.X., Zhang Y.W., Luo Y.F., Jiao X.Y., and Xu J.Z. (2014). Responses of rice yield, irrigation water requirement and water use efficiency to climate change in China: historical simulation and future projections, Agricultural Water Management, 146, 249-261.

Wilby R.L., Wigley T.M.L., Conway D., Jones P.D., Hewitson B.C., Main J., and Wilks D.S. (1998). Statistical downscaling of general circulation model output: a comparison of methods. Water Resour Res, 34, 2995-3008.

Willmott C.J. (1981). On the validation of models, Physical Geography, 2(2), 184-194.

Woo P.S., Ashari Z.M., İsmail Z.B and Jumaat N.F. (2018). Relationship between teachers' self-efficacy and Instructional strategies applied among secondary school teachers in implementing STEM education, IEEE International Conference on Teaching, Assessment, and Learning for Engineering (TALE), Wollongong, NSW, Australia, 2018, 454-461.

Yang C., Wang N., and Wang S. (2017). A comparison of three predictor selection methods for statistical downscaling, International Journal of Climatology, 37, 1238-1249.

Zhang X., and Yan X. (2015). A new statistical precipitation downscaling method with Bayesian model averaging: a case study in China, Climate Dynamics, 45, 2541-2555. 